\title{
VIBRO-ACTIVETED LIME AS A REGULATOR OF CONCRETE HARDENING
}

\author{
$\underline{\text { Andrii Zahrai }}{ }^{1}$, Zenon Borovets \\ 1. Department of Chemical Technology of Silicate Material, Lviv Polytechnic National University, \\ UKRAINE, Lviv, 12 Bandera str., E-mail: andriizahrai@gmail.com, zb_Lviv@ukr.net
}

\begin{abstract}
It is established that the maximum increase in compressive strength is achieved within the limits of $35-40 \%$.
\end{abstract}

Keywords - lime, cement, compressive strength, vibro-activation, additive, dispersion.

In the technology of obtaining concrete products the actual task is to increase their strength through the introduction of special chemical applications. Particularly widespread use was made of salts of alkaline and alkaline earth metals formed with strong acids $\left(\mathrm{CaCl}_{2}, \mathrm{Na}_{2} \mathrm{SO}_{4}\right.$ and others), which are injected up to $2 \%$ of the weight of cement directly during mixing the raw material mixture with water. However, along with the positive effect of increasing the strength of hardened products in the process of their operation, it is also possible to form the salt outlets on the surface and reduce their corrosion resistance.

It is also known that the increase in strength is facilitated by the small supplement of quenched lime diluted with water breeding. The use of quenched lime prevents the formation of salt outlets and reduces the corrosion resistance of products, but this supplement gives a slight increase in firmness, which does not exceed 5\%. A promising direction is the use of the supplement of quenched lime, which was subjected to previous vibration activation.

Vibro-activated lime is characterized with a much higher dispersion in comparison to the usual quench, resulting in a higher specific surface, and hence reactivity. Vibro-activation of quenched lime was carried out on an experimental laboratory vibration plant, designed on the basis of a vibration bunker, for 10-60 minutes. As the results of research showed most intensively, the process of dispersion occurs in the first 20-30 minutes of treatment, and then slowed down due to inverse aggregation of particles and their adhesion on the working surfaces of the plant [1].

It is also found out that the introduction of activated lime application of optimum dispersion parameters in the amount of $2 \%$ of the weight of cement increases the brand strength of the cement stone by $35-40 \%$. In addition, the use of the supplement of vibration activated lime increases the plasticity of the prepared concrete mix.

The conducted studies have shown that along with the existing methods of activation of concrete hardening processes, this method is promising and at the same time technological, which at low cost allows to effectively influence the processes of hardening and significantly increases the quality of finished products.

[1] L. M. Sulimenko, “The general technology of silicates”, Textbook, Moscow, 41-42, 2004. 